\title{
Influence of Race, Gender, and Socioeconomic Status on Binge Eating Frequency in a Population-Based Sample
}

\author{
Patricia Reagan, $\mathrm{PhD}^{1 *}$ \\ Joni Hersch, $\mathrm{PhD}^{2}$
}

\begin{abstract}
Objective: This study investigates race and gender differences in the demographic and socioeconomic determinants of frequency of binge eating using a population-based sample.

Method: An analysis of self-reported data on 573 women and 360 men (range, 18-97 years) from a cross-sectional, multistage area probability sample of individuals aged 18 years and older residing in the Detroit metropolitan area conducted in 1995.
\end{abstract}

Results: For women, the frequency of binge eating is negatively associated with age and family income, and positively associated with being married, depression, and time residing in polluted neighborhoods. For men, the frequency of binge eating is negatively associated with age. The frequency of binge eating was not affected by education, race, obesity, or current dieting.

Conclusion: The frequency of binge eating is highest among adults younger than 40 years. It follows an income gradient for women, but not for men. After controls for individual disadvantage, there is no residual Black/White difference in binge eating. () 2005 by Wiley Periodicals, Inc.

Keywords: race; gender; binge eating; age

(Int J Eat Disord 2005; 38:252-256)

\section{Introduction}

Binge eating is characterized by the consumption of a definitely larger amount of food than most people would eat during a similar period and under similar circumstances (Beglin \& Fairburn, 1992; Fairborn \& Cooper,1993). ${ }^{1}$ Binge eating is closely linked with obesity (Yanovski, 2002; Yanovski, Nelson, Dubbert, \& Spitzer, 1993). Some researchers, such as Yanovski (2003), argue that effective treatment for binge eating would reduce the prevalence of obesity. Most studies of binge eating have used selected samples, primarily obese individuals seeking obesity treatment or those with Type II diabetes, as binge eating is a common symptom among these individuals (Bulik \& Reichborn-Kjennerud, 2003). There is evidence that rates of binge eating are higher among obese individuals, thus limiting the generality of studies of binge eating based on obese individuals. For example, Linde et al. (2004) summarize the literature indicating that the prevalence of binge eating is $2 \%-3 \%$ in community samples and $23 \%-55 \%$ in individuals seeking clinical treatment for obesity.

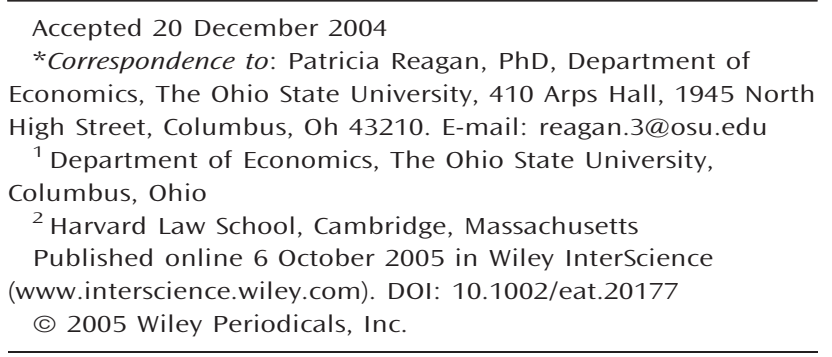

Binge eating is associated with psychological problems such as depression, and may also be a source of health problems net of the effect of obesity (Bulik \& Reichborn-Kjennerud, 2003).

Among the general nonobese population, little is known about the frequency of binge eating and about the demographic and socioeconomic correlates of binge eating frequency. As Striegel-Moore and Franko (2003) point out, studies of the demographic profiles of binge eating and full-blown BED have focused primarily on only two variables, that is, race and gender. Although the traditional eating disorders of anorexia nervosa (AN) and bulimia nervosa (BN) overwhelmingly occur among White girls and White young women, existing evidence suggests that binge eating occurs at a similar frequency among Blacks and Whites and men and women. A community study conducted in Australia found that regular binge eating, at least once per week, occurs as frequently among men (3\%) as among women (3.4\%) (Hay, 1998). In a youngadult American sample, Lewinsohn, Seeley, Moerk, and Striegel-Moore (2002) report no gender difference in episodes of overeating that met the scoring criteria of the Eating Disorders Examination (EDE), although other research suggests a

\footnotetext{
${ }^{1}$ Binge eating was described by Stunkard in 1959, but binge eating disorder (BED) was not introduced until the publication of the 4th ed. of the Diagnostic and Statistical Manual of Mental Disorders (DSM-IV) in 1994 (American Psychiatric Association, 1994).
} 
somewhat greater prevalence of bingeing among women, with the male-to-female ratio of full-blown BED of 2:3 (Spitzer et al., 1992, 1993). Furthermore, there is some evidence that binge eating, at least twice a week during the preceding 3 months, is at least as common among African American women (4.5\%) as among White women (2.6\%) (Striegel-Moore, Wilfley, Pike, Dohm, \& Fairburn, 2000). French et al. (1997) find no race/ethnic differences in the psychosocial factors that underlie binge eating among adolescent girls. One study that examined age and education in addition to race among women is Fitzgibbon et al. (1998), who report that age explained $1 \%$ of the variance in binge eating severity and that education was not a significant predictor within a sample of White, Black, and Hispanic women.

This study examines the connection between race, gender, age, education, socioeconomic status, and psychological distress on frequency of binge eating using a population-based sample from the Detroit metropolitan area.

\section{Methods}

The Detroit Area Study, 1995: Social Influences on Health: Stress, Racism, and Health Protective Resources provides a sample of 1,139 respondents in the Detroit area. (Jackson \& Williams, 2002). The Detroit Area Studies series was initiated in 1951 at the University of Michigan, and new surveys, focusing on varying topics, have been conducted in most years since then. Face-to-face interviews are conducted by University of Michigan graduate students in a research training practicum in survey research and by professional interviewers from the Survey Research Center of the Institute for Social Research at the University of Michigan. The sampling frame is a multistage area probability sample of individuals 18 years and older residing in the Detroit metropolitan area and surrounding suburban areas, which included the counties of Wayne, Oakland, and Macomb. Black households are oversampled.

The 1995 survey included self-reported information on binge eating and on dieting behavior, as well as information on height and current weight. The binge eating question asked: "Now, we would like to ask you about your eating habits. How often do you have an eating binge in which you eat a lot of food within a few hours?" Respondents had seven options: never, less than once a month, once a month, 2-3 days per month, weekly, 2-3 days per week, and most days. ${ }^{2}$ Our analyses are based on ordered

\footnotetext{
${ }^{2}$ The American Psychiatric Association' definition of BED in DSM-IV is far more restrictive and includes recurrent episodes of binge eating, combined with a feeling of lack of control over eating during the episode, with a minimum average occurrence of 2 days per week over at least 6 months.
}

logit analyses of the frequency of bingeing. We calculate body mass index (BMI) from self-reported information on weight and height. Individuals are classified as obese if their BMI is $\geq 30$.

Available demographic and socioeconomic information included age, gender, race/ethnicity, marital status, education, and family income. A measure of cumulative exposure to neighborhood disadvantage was also available. Respondents were asked if they had ever resided in an area "where residents have problems such as skin or eye irritation, breathing difficulties, or even cancers because of exposure to things like pollution, hazardous chemicals or waste incinerators.” A follow-up question asked for the number of years the respondent lived in such a neighborhood. The number of years of exposure is divided by the respondent's age to measure the fraction of their lives spent in such a neighborhood.

Race/ethnicity was reported in six categories of White, Black/African American, Asian, American Indian, Hispanic, and other. Only 33 respondents were neither White nor Black, so we exclude those observations. We define indicator variables for whether the individual was $\geq 65$ years, 40-64 years, and 18-39 years.

Marital status was reported as married, living with a partner at least 6 months, widowed, divorced, separated, or never married. We define an indicator variable equal to one for those married or living with a partner. Education was grouped into three categories: high school dropouts with less than 12 years of education, high school graduates with 12-15 years of schooling, and college graduates with at least 16 years of schooling.

Family income was requested in the survey, with respondents given the option of reporting actual total household income before taxes in 1994, or choosing among 16 categories. Approximately one half of the respondents opted to report income in categories rather than report a dollar amount. When respondents reported categorical income, we imputed their income as the mean of that category. In the analysis, we used the natural log of family income so that the coefficient reflects the protective effect of a percentage change in income rather than an absolute change in income.

A depression scale was based on the responses to six questions about the frequency of feeling sad, worthless, hopeless, and that everything is an effort, and experiencing nervousness and restlessness. The responses were reversed coded so that higher values represent greater frequency and took values of (1) never, (2) hardly ever, (3) not too often, (4) fairly often, and (5) very often. The responses to each of the questions were summed and the total was divided by 6 . An indicator variable for depressed symptoms was created if the respondent scored 3-5 on this scale.

The original sample consisted of 717 women and 422 men. The study sample consisted of 573 women and 360 
men who provided valid responses to all the questions used in the analysis.

This research was reviewed and approved by an institutional review board.

\section{Results}

The frequencies of binge eating, disaggregated by race, gender, and obesity, are reported in Table 1. We used a Kolmogorov-Smirov test for the equality of the distributions across different groups. Holding constant race and gender, only White men displayed a statistically significant difference in the distribution of binge eating by obesity. Obese White men binge more frequently than nonobese White men. There was no significant difference in the distribution of the frequency of binge eating between obese and nonobese White women, obese and nonobese Black women, and obese and nonobese Black men. There were no Black/White differences in the distributions of frequencies of bingeing by gender and obesity category. There were no gender differences in the distribution of the frequencies of bingeing by race and obesity categories.

The frequencies of sample characteristics, stratified by gender, are reported in Table 2. Approximately $14 \%$ of men and women report binge eating either most days or at least 2 days per week. On the basis of the current BMI, $33 \%$ of the women and $22 \%$ of the men were obese. Among women, $58 \%$ were Black; among men, $46 \%$ were Black. The ages of the women were as follows: $43 \%$ were $18-39$ years, $37 \%$ were $40-64$ years, and $20 \%$ were $>65$ years. The men were slightly younger: $45 \%$ were $18-39$ years, $41 \%$ were 40-64 years, and 15\% were $>65$ years.

Among women, $27 \%$ were classified as reporting depressed symptoms, but only $8 \%$ of men were classified as reporting depressed symptoms. Dieting was common, with $51 \%$ of women and $33 \%$ of the men currently on a diet. Turning to measures of educational attainment, $17 \%$ of the women and $15 \%$ of the men were high school dropouts; $64 \%$ of the women and $57 \%$ of the men had graduated from high school but not graduated from college; and $19 \%$ of the women and $28 \%$ of the men were college graduates. The rate of marriage or cohabitation was $35 \%$ for women and $53 \%$ for men. The mean family income for women was $\$ 35,651$, whereas the mean family income for men was $\$ 50,383$. Both men and women reported having spent on average approximately $5 \%$ of their lives in neighborhoods where residents had health problems associated with exposure to pollution, hazardous chemicals, or waste incinerators.

The adjusted odds ratios (OR) and 95\% confidence intervals (CI) are reported in Table 3 for an ordered logistic model of frequency of binge eating estimated separately for women and men. Obesity did not have a statistically significant effect on the frequency of bingeing for either men or women. Race did not have a statistically significant effect. For both men and women, the frequency of bingeing declined with age, but the decline in frequency of bingeing began at an earlier age for men than for

TABLE 1. Frequency of binge eating by gender, race, and obesity status

\begin{tabular}{|c|c|c|c|c|c|c|c|c|}
\hline \multirow[b]{3}{*}{ Binge Eating } & \multicolumn{4}{|c|}{ Women } & \multicolumn{4}{|c|}{ Men } \\
\hline & \multicolumn{2}{|c|}{ Nonobese } & \multicolumn{2}{|c|}{ Obese } & \multicolumn{2}{|c|}{ Nonobese } & \multicolumn{2}{|c|}{ Obese } \\
\hline & Number & Percent & Number & Percent & Number & Percent & Number & Percent \\
\hline \multicolumn{9}{|l|}{ White: } \\
\hline Never & 76 & 41.53 & 14 & 24.56 & 73 & 46.50 & 9 & 23.08 \\
\hline Less than once a month & 34 & 18.58 & 11 & 19.30 & 20 & 12.74 & 10 & 25.64 \\
\hline Once a month & 26 & 14.21 & 8 & 14.04 & 20 & 12.74 & 4 & 10.26 \\
\hline 2-3 days per month & 17 & 9.29 & 7 & 12.28 & 18 & 11.46 & 4 & 10.26 \\
\hline Once a week & 17 & 9.29 & 8 & 14.04 & 12 & 7.64 & 7 & 17.95 \\
\hline 2-3 days per week & 7 & 3.83 & 4 & 7.02 & 7 & 4.46 & 3 & 7.69 \\
\hline Most days & 6 & 3.28 & 5 & 8.77 & 7 & 4.46 & 2 & 5.13 \\
\hline Sample size & 183 & & 57 & & 157 & & 39 & \\
\hline \multicolumn{9}{|l|}{ Black: } \\
\hline Never & 86 & 42.57 & 55 & 41.98 & 57 & 46.34 & 20 & 48.78 \\
\hline Less than once a month & 17 & 8.42 & 9 & 6.87 & 13 & 10.57 & 5 & 12.20 \\
\hline Once a month & 29 & 14.36 & 16 & 12.21 & 15 & 12.20 & 1 & 2.44 \\
\hline 2-3 days per month & 23 & 11.39 & 13 & 9.92 & 4 & 3.25 & 3 & 7.32 \\
\hline Once a week & 14 & 6.93 & 11 & 8.40 & 10 & 8.13 & 5 & 12.20 \\
\hline 2-3 days per week & 20 & 9.89 & 10 & 7.63 & 12 & 9.76 & 4 & 9.76 \\
\hline Most days & 13 & 6.44 & 17 & 12.98 & 12 & 9.76 & 3 & 7.32 \\
\hline Sample size & 202 & & 131 & & 123 & & 41 & \\
\hline
\end{tabular}


TABLE 2. Sample characteristics by gender

\begin{tabular}{|c|c|c|c|c|}
\hline \multirow{2}{*}{$\begin{array}{l}\text { Discrete } \\
\text { Variables }\end{array}$} & \multicolumn{2}{|c|}{ Women } & \multicolumn{2}{|c|}{ Men } \\
\hline & Frequency & Percent & Frequency & Percent \\
\hline \multicolumn{5}{|l|}{ Binge eating } \\
\hline Never & 231 & 40.31 & 159 & 44.17 \\
\hline \multicolumn{5}{|l|}{ Less than once } \\
\hline a month & 71 & 12.39 & 48 & 13.33 \\
\hline Once a month & 79 & 13.79 & 40 & 11.11 \\
\hline \multicolumn{5}{|l|}{$2-3$ days per } \\
\hline month & 60 & 10.47 & 29 & 8.06 \\
\hline Once a week & 50 & 8.73 & 34 & 9.44 \\
\hline 2-3 days per week & 41 & 7.16 & 26 & 7.22 \\
\hline Most days & 41 & 7.16 & 24 & 6.67 \\
\hline \multicolumn{5}{|l|}{$\mathrm{BMI}$} \\
\hline $\mathrm{BMI}<30$ & 385 & 67.19 & 280 & 77.78 \\
\hline $\mathrm{BMI} \geq 30$ & 188 & 32.81 & 80 & 22.22 \\
\hline \multicolumn{5}{|l|}{ Race } \\
\hline White & 240 & 41.88 & 196 & 54.44 \\
\hline Black & 333 & 58.12 & 164 & 45.56 \\
\hline \multicolumn{5}{|l|}{ Age } \\
\hline $18 \leq$ age $<40$ & 248 & 43.28 & 161 & 44.72 \\
\hline $40 \leq$ age $<65$ & 213 & 37.17 & 146 & 40.56 \\
\hline $65 \leq$ age & 112 & 19.55 & 53 & 14.72 \\
\hline \multicolumn{5}{|l|}{ Depression } \\
\hline Depressed & 153 & 26.70 & 28 & 7.78 \\
\hline Not depressed & 420 & 73.30 & 332 & 92.22 \\
\hline \multicolumn{5}{|l|}{ Diet } \\
\hline \multicolumn{5}{|l|}{ Currently } \\
\hline on diet & 294 & 51.31 & 118 & 32.78 \\
\hline Not currently & & & & \\
\hline on diet & 279 & 48.69 & 242 & 67.22 \\
\hline \multicolumn{5}{|l|}{ Education } \\
\hline Education < 12 & 95 & 16.58 & 55 & 15.28 \\
\hline \multicolumn{5}{|l|}{$12 \leq$ education } \\
\hline$<16$ & 369 & 64.40 & 205 & 56.94 \\
\hline Education $\geq 16$ & 109 & 19.02 & 100 & 27.78 \\
\hline \multicolumn{5}{|l|}{ Married } \\
\hline \multicolumn{5}{|l|}{ Married or } \\
\hline cohabitating & 199 & 34.73 & 192 & 53.33 \\
\hline Unmarried & 374 & 65.27 & 168 & 46.67 \\
\hline \multirow{2}{*}{$\begin{array}{l}\text { Continuous } \\
\text { Variables }\end{array}$} & & Standard & & Standard \\
\hline & Mean & Deviation & Mean & Deviation \\
\hline \multirow{5}{*}{$\begin{array}{l}\text { Family income } \\
\text { Bad environment } \\
\text { Fraction of } \\
\text { life spent in bad } \\
\text { neighborhood } \\
\text { Sample size }\end{array}$} & $\$ 35,650.99$ & $\$ 33,828.27$ & $\$ 50,383.19$ & $\$ 37,743.9$ \\
\hline & & & & \\
\hline & & & & \\
\hline & 0.05 & 0.17 & 0.05 & 0.17 \\
\hline & 573 & & 360 & \\
\hline
\end{tabular}

Note: $\mathrm{BMI}=$ body mass index.

women. The adjusted OR of frequency of bingeing among women $\geq 65$ years was $0.28(95 \% \mathrm{CI}=0.18$ 0.44 ) relative to women 18-39 years. However, women 40-64 years were no less likely than women 18-39 years to binge more frequently. The adjusted OR of frequency of bingeing for men 40-64 years was 0.37 (95\% CI $=0.24-0.58)$. The adjusted OR of frequency of bingeing for men $\geq 65$ years was 0.16 (95\% CI $=0.08-0.32$ ). Depressed symptoms significantly increased the frequency of bingeing for women. The adjusted odds ratio was 1.79 (95\% CI $=1.26-2.53$ ). There was no statistically significant effect of depression for men. The frequency of binge eating was not affected by being on a diet
TABLE 3. Ordered logit model of frequency of binge eating

\begin{tabular}{|c|c|c|c|c|}
\hline \multirow[b]{2}{*}{ Discrete Variables } & \multirow[b]{2}{*}{ OR } & \multirow{2}{*}{$\frac{\text { Women }}{95 \% \mathrm{Cl}}$} & \multirow[b]{2}{*}{ OR } & \multirow{2}{*}{$\begin{array}{c}\text { Men } \\
95 \% \mathrm{Cl}\end{array}$} \\
\hline & & & & \\
\hline \multicolumn{5}{|l|}{ BMI } \\
\hline $\mathrm{BMI}<30$ & 1.00 & & 1.00 & \\
\hline $\mathrm{BMI} \geq 30$ & 1.35 & $0.96-1.91$ & 1.29 & $0.80-2.10$ \\
\hline \multicolumn{5}{|l|}{ Race - } \\
\hline White & 1.00 & & 1.00 & \\
\hline Black & 0.81 & $0.58-1.14$ & 0.95 & $0.62-1.45$ \\
\hline \multicolumn{5}{|l|}{ Age } \\
\hline $18 \leq$ age $<40$ & 1.00 & & 1.00 & \\
\hline $40 \leq$ age $<65$ & 0.85 & $0.60-1.20$ & 0.37 & $0.24-0.58$ \\
\hline $65 \leq$ age & 0.28 & $0.18-0.44$ & 0.16 & $0.08-0.32$ \\
\hline \multicolumn{5}{|l|}{ Depression } \\
\hline Depressed & 1.79 & $1.26-2.53$ & 2.05 & $0.95-2.25$ \\
\hline Not depressed & 1.00 & & 1.00 & \\
\hline \multicolumn{5}{|l|}{ Diet } \\
\hline Currently on diet & 1.15 & $0.84-1.58$ & 1.45 & $0.93-2.25$ \\
\hline on diet & 1.00 & & 1.00 & \\
\hline \multicolumn{5}{|l|}{ Education } \\
\hline Education < 12 & 0.98 & $0.62-1.53$ & 0.80 & $0.42-1.52$ \\
\hline $12 \leq$ education $<16$ & 1.00 & & 1.00 & \\
\hline Education $\geq 16$ & 1.11 & $0.74-1.68$ & 0.78 & $0.49-1.24$ \\
\hline \multicolumn{5}{|l|}{ Married -} \\
\hline Married & 1.44 & $1.01-2.06$ & 0.76 & $0.49-1.16$ \\
\hline Unmarried & 1.00 & & 1.00 & \\
\hline \multicolumn{5}{|l|}{ Continuous Variables } \\
\hline \multicolumn{5}{|l|}{ Family income } \\
\hline $\begin{array}{l}\text { Natural log of } \\
\text { family income }\end{array}$ & 0.64 & $0.53-0.76$ & 0.84 & $0.65-1.08$ \\
\hline \multicolumn{5}{|l|}{ Bad environment } \\
\hline $\begin{array}{l}\text { Fraction of life spent } \\
\text { in bad neighborhood }\end{array}$ & 2.83 & $1.19-6.74$ & 1.69 & $0.55-5.18$ \\
\hline
\end{tabular}

Note: $\mathrm{OR}=$ odds ratio; $95 \% \mathrm{Cl}=95 \%$ confidence interval; $\mathrm{BMI}=$ body mass index.

or education for either men or women. Married women had an adjusted OR of $1.44(95 \% \mathrm{CI}=1.01-$ 2.06). Marital status had no statistically significant effect on frequency of bingeing for men.

For women, the frequency of binge eating decreased with log family income. The estimates suggest that the adjusted OR for a $10 \%$ increase in family income is $0.958(95 \% \mathrm{CI}=0.942-0.975)$. The fraction of time spent in a neighborhood with an unhealthy environment increases the frequency of bingeing for women. The estimates suggest that if a woman lived $10 \%$ more of her life in a neighborhood with an unhealthy environment, the adjusted OR for frequency of bingeing would be 1.11 (95\% $\mathrm{CI}=1.02-1.21$.

\section{Conclusion}

This is the first study to try to explain the frequency of binge eating in a population-based sample of adults. A comparison of the distributions of bingeing 
frequency shows no gender differences, holding constant race and obesity status. Furthermore, there is not a statistically significant difference in the distribution of bingeing frequencies between Blacks and Whites, holding constant gender and obesity status. Only White men display a statistically significant difference in the distributions of binge frequency by obesity status. Our regression results, stratified by gender, show no statistically significant effect on the adjusted ORs of race or obesity status.

Among men, only age has a statistically significant effect on the frequency of binge eating. The frequency of bingeing declines by age 40 and further declines at age 65 years. The frequency of bingeing in men of comparable ages is unaffected by depressive symptoms, education, marital status, income, and cumulative exposure to neighborhood disadvantage.

The frequency of bingeing among women, conversely, does not begin to decline until age 65 . The frequency is increased by depressive symptoms, being married, and spending a large fraction of their lives in disadvantaged neighborhoods. Higher family income decreases the frequency of bingeing, and the frequency of bingeing is unaffected by education.

Our results indicate that the social environment plays a far greater role in explaining frequency of bingeing in women than in men. We note, however, that the sample size for men is only two-thirds that for women, and it is possible that the gender difference in statistical significance of the socioeconomic factors is attributable to the smaller sample size for men.

Some limitations of our data are obvious. We do not have longitudinal data on the individual's history of binge eating frequency, nor whether the quantity eaten that prompted respondents to report binge eating was objectively large. Although we do not find race or gender differences in the distribution of self-reported frequency of bingeing, our results do not suggest that there are no race or gender differences in BED. However, our data do not allow us to test this hypothesis because the information in the data set falls far short of allowing a definite classification of BED. We, therefore, do not claim that we are adding to the literature on BED. Our focus is to examine the importance of demographic and socioeconomic factors on frequency of binge eating, as characterized by the respondent, in a population-based sample of White and Black adult men and women.

\section{References}

American Psychiatric Association. (1994). Diagnostic and statistical manual of mental disorders (4th ed.). Washington, DC: Author.

Beglin, S.J., \& Fairburn, C.G. (1992). What is meant by the term "binge"? American Journal of Psychiatry, 149, 123-124.

Bulik, C.M., \& Reichborn-Kjennerud, T. (2003). Medical morbidity in binge eating disorder. International Journal of Eating Disorders, 34, S39-S46.

Fairburn, C.G., \& Cooper, Z. (1993). The Eating Disorder Examination (12th ed.). In C.G. Fairburn \& G.T. Wilson (Eds.), Binge eating: Nature, assessment and treatment.pp (317-360). New York: Guilford Press.

Fitzgibbon, M.L., Spring, B., Avellone, M.E., Blackman, L.R., Pingitore, R., \& Stolley, M.R. (1998). Correlates of binge eating in Hispanic, black, and white women. International Journal of Eating Disorders, 24, 43-52.

French, S.A., Story, M., Neumark-Sztainer, D., Downes, B., Resnick, M., \& Blum, R. (1997). Ethnic differences in psychosocial and health behavior correlates of dieting, purging, and binge eating in a population-based sample of adolescent females. International Journal of Eating Disorders, 22, 315-322.

Hay, P. (1998). The epidemiology of eating disorder behaviors: An Australian community-based survey. International Journal of Eating Disorders, 23, 371-382.

Jackson, J. \& Williams, D. (2002). Detriot Area Study, 1995: Social Influences on Health: Stress, Racism and Health Protective resources. ICPSR version. Ann Arloor, MI: University of Michigan.

Lewinsohn, P.M., Seeley, J.R., Moerk, K.C., \& Striegel-Moore, R.H. (2002). Gender differences in eating disorder symptoms in young adults. International Journal of Eating Disorders, 32, 426-440.

Linde, J.A., Jeffery, R.W., Levy, R.L., Sherwood, N.E., Utter, J., Pronk, N.P., \& Boyle, R.G. (2004). Binge eating disorder, weight control self-efficacy, and depression in overweight men and women. International Journal of Obesity and Related Metabolic Disorders, 28, 418-425.

Spitzer, R.L., Devlin, M.J., Walsh, B.T., Hasin, D., Wing, R.R., Marcus, M.D., Stunkard, A., Wadden, T., Yanovski, S., Agras, W.S., \& Nonas, C. (1992). Binge eating disorder: A multisite field trial of the diagnostic criteria. International Journal of Eating Disorders, 11, 191-203.

Spitzer, R.L., Yanovski, S.Z., Wadden, T., Wing, R.R., Marcus, M.D., Stunkard, A., Devlin, M.J., Hasin, D., \& Horne, R.L. (1993). Binge eating disorder: Its further validation in a multisite study. International Journal of Eating Disorders, 13, 137153.

Striegel-Moore, R.H., \& Franko, D.L. (2003). Epidemiology of binge eating disorder. International Journal of Eating Disorders, 34, S19-S29.

Striegel-Moore, R.H., Wilfley, D.E., Pike, K.M., Dohm, F.A., \& Fairburn, C.G. (2000). Recurrent binge eating in black American women. Archives of Family Medicine, 9, 83-87.

Stunkard, A.J. (1959). Eating patterns and obesity. Psychiatry Quarterly, 33, 284-292.

Yanovski, S.Z. (2002). Binge eating in obese persons. In C.G. Fairburn \& K. Brownell (Eds.), Eating disorders and obesity (Vol. 2., pp 403-407). New York: Guilford Press.

Yanovski, S.Z. (2003). Binge eating disorder and obesity in 2003: Could treating an eating disorder have a positive effect on the obesity epidemic? International Journal of Eating Disorders, 34, S117-S120.

Yanovski, S.Z., Nelson, J.E., Dubbert, B.K., \& Spitzer, R.L. (1993). Association of binge eating disorder and psychiatric comorbidity in the obese. American Journal of Psychiatry, 150, 14721479. 